\title{
Acute Kidney Injury Following Exposure to Calcineurin Inhibitors in a Patient with Idiopathic Membranous Nephropathy
}

\author{
Maciej Goździk ${ }^{1,2} \cdot$ Agnieszka Płuciennik $^{2}$ - Anna Zawiasa-Bryszewska ${ }^{1,2} \cdot$ Maja Nowicka $^{1}$ • Zuzanna Nowicka ${ }^{1}$. \\ Małgorzata Wągrowska-Danilewicz ${ }^{3} \cdot$ Ilona Kurnatowska ${ }^{1,2}$
}

Published online: 5 October 2019

(c) The Author(s) 2019

\begin{abstract}
Membranous nephropathy (MN) is one of the most common causes of nephrotic syndrome in non-diabetic adult patients; $75 \%$ of adult patients with MN suffer from primary idiopathic membranous nephropathy (IMN). The treatment of choice is immunosuppressive therapy, with a combination of steroids and cyclophosphamide (CYF) or chlorambucil or, as second-line treatment, calcineurin inhibitors (CNIs). One of the main concerns associated with the usage of CNIs is their potential to induce nephrotoxicity. We report a case of acute kidney injury that developed on two separate occasions within days of the administration of CNIs in a 57-year-old male patient treated for MN. The patient was qualified for first-line treatment with prednisone and CYF. Due to insufficient response and bad tolerance of CYF infusions, the immunosuppressive regimen was modified and CNIs were introduced, starting with cyclosporine A (CsA). On the third day of treatment, a severe decrease in diuresis and kidney function occurred and CsA was discontinued, resulting in a return to baseline kidney function. After 2 months, the situation repeated after attempting to introduce tacrolimus.
\end{abstract}

Ilona Kurnatowska

ilona.kurnatowska@umed.lodz.pl

Maciej Goździk

maciej.j.gozdzik@gmail.com

Agnieszka Płuciennik agapluciennik@o2.pl

Anna Zawiasa-Bryszewska

ania_zawiasa@go2.pl

Maja Nowicka

maja.a.nowicka@gmail.com

Zuzanna Nowicka

zuzannow@gmail.com

Małgorzata Wagrowska-Danilewicz

malgorzata.wagrowska-danilewicz@umed.lodz.pl

1 Department of Clinical Pharmacology, 1st Chair of Internal Medicine, Medical University of Łódź, ul. Kopcińskiego 22, 90-153 Lodz, Poland

2 Department of Nephrology, Norbert Barlicki Memorial Teaching Hospital, Lodz, Poland

3 Department of Nephropathology, Medical University of Lodz, Lodz, Poland

\section{Key Points}

Calcineurin inhibitors are drugs that may exert a potentially toxic effect in the kidneys, which in turn might increase the risk of renal insufficiency progression in patients.

Acute kidney injury developed within days of initiating calcineurin inhibitor therapy (first cyclosporine A and later tacrolimus) in a patient being treated for membranous nephropathy.

\section{Introduction}

Membranous nephropathy (MN) is one of the most common causes of nephrotic syndrome in non-diabetic adult patients [1]. It is estimated that $75 \%$ of adult patients with MN suffer from primary idiopathic membranous nephropathy (IMN). In patients with $\mathrm{MN}$, a secondary cause of the disease should be excluded: most commonly a neoplasm, viral infection or a systemic disease like lupus nephritis [2,3]. According 
to current records IMN is either the second or third most frequent cause of end-stage renal disease [4]. Long-term prognosis depends on whether remission is obtained.

One characteristic feature of IMN is spontaneous remissions, occurring in about $30 \%$ of patients during the first 2 years of the disease. The probability of remission is inversely related to the daily protein loss [5]. Other prognostic factors of poor clinical outcome include male gender, hypertension, age older than 50 years and impaired kidney function at the beginning [6]. Nephroprotection is the current treatment of choice for IMN and includes maintenance of appropriate arterial blood pressure, proteinuria reduction achieved by inhibition of the renin-angiotensin-aldosterone system, reduction of dietary protein intake and dyslipidemia correction.

If such treatment is inefficient, immunosuppressive therapy is introduced. The treatment of choice is a combination of steroids and cyclophosphamide (CYF) or chlorambucil. In patients for whom this treatment is contraindicated, insufficient or poorly tolerated, the recommended secondline treatment is calcineurin inhibitors (CNIs) [7]. CNIs (previously cyclosporine (CsA) and nowadays increasingly popular tacrolimus [TAC]) are recommended in treatment regimens for glomerulonephropathies with significant proteinuria, such as minimal change disease, focal and segmental glomerulosclerosis and MN [8].

One of the main concerns associated with the use of CNIs is their potential to induce nephrotoxicity. Kidney injury following treatment with CNIs may be acute (AKI) or chronic $[9,10]$. This complication is relatively well-described; however, large studies have only evaluated transplant recipients.

Both CsA and TAC may induce a dose-dependent reduction in the glomerular filtration rate (GFR), caused predominantly by diminished renal blood flow, which is associated with contraction of the afferent and efferent arteriole [11, 12]. Renal vessel contraction that accounts for these reversible changes has been proven to be caused by increased activation of the sympathetic system in the kidney [13], stimulation of the renin-angiotensin system, elevated production of thromboxane $\mathrm{A} 2$, a diminution in production of vesseldiluting prostaglandins and increased endothelin secretion in the kidney [14].

The incidence of chronic kidney disease (CKD) with an estimated GFR (eGFR) diminution below $29 \mathrm{~mL} /$ $\mathrm{min} / 1.73 \mathrm{~m}^{2}$ ranges from 7 to $21 \%$ in transplant patients and depends on the type of transplanted organ and the duration of drug intake [15]. In more severe cases and upon prolonged treatment, CNIs have the potential to damage renal arterioles and induce interstitial lesion formation, mainly nodular hyalinosis and mucinous thickening of the tunica intima, which in turn can lead to vascular contraction or, in severe cases, to occlusion [16]. Other renal effects of CNIs include tubular dysfunction and, rarely, hemolytic uremic syndrome (HUS) that can lead to acute graft loss [17]. Interstitial fibrosis could be also considered as a cause of CKD, most plausibly associated with excessive production of transforming growth factor beta (TGF- $\beta$ ) [18]. A similar pattern of renal injury from CsA is seen with the use of TAC, thereby suggesting a drug class effect [19].

We report a case of AKI in a patient with nephrotic syndrome during IMN in the course of CNI treatment. Written informed consent was obtained from the patient for publication of this case report and any accompanying images. A copy of the written consent may be requested for review from the corresponding author.

\section{Case History}

A 57-year-old, white male patient with nephrotic syndrome due to IMN was admitted to the Nephrology Department because of edema, with high proteinuria despite immunosuppressive therapy applied previously. He was hypertensive and obese, with a history of myocardial infarction treated conservatively in 1995 , coronary artery bypass surgery in 2005 and multiple coronary interventions in 2016.

In March 2016, the patient experienced edema in the lower extremities, with nephrotic syndrome characteristics in laboratory tests: urinalysis: urine specific gravity 1.015 , protein $570.7 \mathrm{mg} / \mathrm{dL}$, leukocytes $3.77 / \mu \mathrm{L}$, erythrocytes $32.06 /$ $\mu \mathrm{L}$ (with dysmorphic erythrocytes); daily urine protein loss $11.7 \mathrm{~g}$; biochemical tests: serum creatinine level $(\mathrm{Cr})$ $1.33 \mathrm{mg} / \mathrm{dL}$ (eGFR $59.3 \mathrm{~mL} / \mathrm{min} / 1.73 \mathrm{~m}^{2}$ according to the Modification of Diet in Renal Disease [MDRD] formula), serum total protein $5.2 \mathrm{~g} / \mathrm{dL}$, albumin $2.55 \mathrm{~g} / \mathrm{dL}$, alpha1 $0.208 \mathrm{~g} / \mathrm{dL}$, alpha2 $0.931 \mathrm{~g} / \mathrm{dL}$, beta $0.619 \mathrm{~g} / \mathrm{dL}$, beta2 $0.317 \mathrm{~g} / \mathrm{dL}$, and gamma $0.567 \mathrm{~g} / \mathrm{dL}$, with hyperlipidemia: total cholesterol (TC) $226 \mathrm{mg} / \mathrm{dL}$, low-density lipoprotein (LDL) $133 \mathrm{mg} / \mathrm{dL}$, high-density lipoprotein (HDL) $45 \mathrm{mg} /$ $\mathrm{dL}$, and triglycerides (TG) $240 \mathrm{mg} / \mathrm{dL}$.

Renal biopsy revealed changes typical for MN (Fig. 1).

The imaging tests performed were computed tomography of the thorax, abdominal ultrasound, gastroscopy, and colonoscopy. The tumor marker tests performed were prostatespecific antigen (PSA), carcinoembryonic antigen (CEA), and carbohydrate antigen 19-9 (Ca19-9). Virology (hepatitis $\mathrm{C}$ virus antibodies [anti-HCV], hepatitis B core antibodies [anti-HBc], and hepatitis B surface antigen [HBsAg]) did not reveal any secondary cause of glomerulonephritis.

The patient originally qualified for treatment according to the Ponticelli regimen (prednisone and CYF in monthly intravenous infusions). In the fourth month of treatment, the patient experienced acute coronary syndrome. Coronarography revealed an occlusion of the venous bypass vein to the right coronary artery; simultaneously, a stent coated with rapamycin was implanted. In November 2016, the patient 


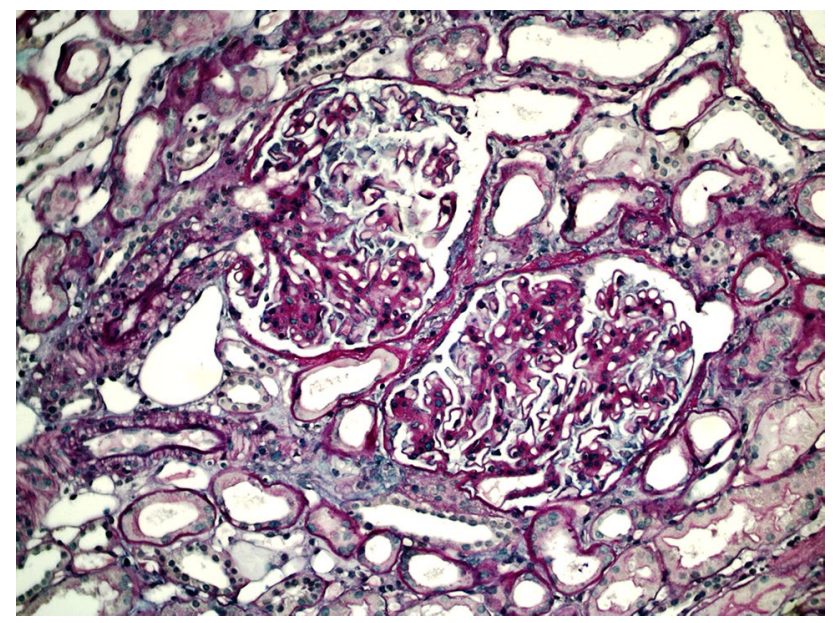

Fig. 1 Kidney biopsy in light microscopy (LM). The renal biopsy containing two glomeruli with diffuse thickening of the capillary walls. Interstitial fibrosis and tubular atrophy were focal and covered less than $10 \%$ of the renal cortex

was admitted to the Nephrology Department due to lack of improvement in the nephritic syndrome and bad tolerance to the treatment. Until admission, the patient had been administered $3.6 \mathrm{~g}$ of CYF, $1500 \mathrm{mg}$ of methylprednisolone, and subsequently prednisone $20 \mathrm{mg} /$ day. Concomitant medication included furosemide $80 \mathrm{mg} /$ day, hydrochlorothiazide $25 \mathrm{mg} /$ day, bisoprolol $2.5 \mathrm{mg} /$ day, lercanidipine $10 \mathrm{mg} /$ day, ramipril $10 \mathrm{mg} /$ day, doxazosin $8 \mathrm{mg} /$ day, rosuvastatin $20 \mathrm{mg} /$ day, acetylsalicylic acid $75 \mathrm{mg} /$ day, clopidogrel $75 \mathrm{mg} /$ day, and pantoprazole $20 \mathrm{mg} /$ day.

On admission, the physical exam revealed peripheral edema, body weight of $114.4 \mathrm{~kg}$ (body mass index [BMI] $36.8 \mathrm{~kg} / \mathrm{m}^{2}$ ), and well-controlled hypertension, with results below $130 / 80 \mathrm{mmHg}$. The laboratory findings revealed the following: daily urine protein loss $17.3 \mathrm{~g}$, hypoproteinemia, hypoalbuminemia (serum total protein $46.5 \mathrm{~g} / \mathrm{L}$, albumins $26.6 \mathrm{~g} / \mathrm{L}$ ), disturbances in lipid metabolism (TC $250 \mathrm{mg} /$ dL, LDL $138 \mathrm{mg} / \mathrm{dL}$, HDL $73 \mathrm{mg} / \mathrm{dL}$, TG $197 \mathrm{mg} / \mathrm{dL}$ ), and good kidney function, with Cr $1.16 \mathrm{mg} / \mathrm{dL}$ and eGFR $69 \mathrm{~mL} /$ $\min / 1.73 \mathrm{~m}^{2}$.

Due to insufficient response to the previously applied treatment and bad tolerance of CYF infusions reported by the patient (nausea, headaches), the decision was made to change the immunosuppressive treatment. Alongside continued $20 \mathrm{mg}$ /day prednisone, CsA was added at a dosage of $150 \mathrm{mg}$ twice a day. On the third day of the treatment, there was a diminution of daily diuresis (with the lowest value $300 \mathrm{~mL}$ ) and a decrease in kidney function $(\mathrm{Cr}$ rose up to $2.8 \mathrm{mg} / \mathrm{dL}$, with an eGFR of $28 \mathrm{~mL} / \mathrm{min} / 1.73 \mathrm{~m}^{2}$ ). The CsA trough level was $186.4 \mathrm{ng} / \mathrm{mL}$. Neither an elevation of blood pressure nor other side effects were observed. Considering an evident relationship between the deterioration of kidney function and the administration of CsA, the
CNI medication was discontinued. After the termination of the treatment, proper diuresis was obtained (up to $2000 \mathrm{~mL}$ daily) and kidney function improved (with $\mathrm{Cr} 1.4 \mathrm{mg} / \mathrm{dL}$ and eGFR $53 \mathrm{~mL} / \mathrm{min} / 1.73 \mathrm{~m}^{2}$ on the third day following discontinuation). During that time, no other changes were made in the associated treatment, including prednisone at the dosage of $20 \mathrm{mg} /$ day.

Rehospitalization occurred after 2 months (January 2017). The patient was in good general condition, with little edema in the lower extremities and an arterial blood pressure of $125 / 75 \mathrm{mmHg}$. In laboratory tests, there was persisting characteristics of nephrotic syndrome, with a daily urine protein loss of $13 \mathrm{~g}$, with preserved kidney function (Cr $1.08 \mathrm{mg} / \mathrm{dL}$, eGFR $73 \mathrm{~mL} / \mathrm{min} / 1.73 \mathrm{~m}^{2}$ ).

During the hospitalization, treatment (prednisone $10 \mathrm{mg}$ ) was modified by adding TAC at a dosage of $0.1 \mathrm{mg} / \mathrm{kg}$ twice a day.

On the second day of TAC administration, there was a reduction in diuresis (to $300 \mathrm{~mL} /$ day) and deterioration in kidney function (with Cr $2.3 \mathrm{mg} / \mathrm{dL}$ and eGFR $28 \mathrm{~mL} /$ $\min / 1.73 \mathrm{~m}^{2}$ ). The treatment with TAC was stopped. On the next day after discontinuation, diuresis returned, alongside a gradual decrease in $\mathrm{Cr}$, down to $1.5 \mathrm{mg} / \mathrm{dL}$; by the third day the eGFR reached the level of $52 \mathrm{~mL} / \mathrm{min} / 1.73 \mathrm{~m}^{2}$.

Due to the second AKI incident, we decided to begin treatment with rituximab. After two injections of $1000 \mathrm{mg}$ of rituximab, we observed complete remission.

\section{Discussion}

In the patient described (with heavy nephrotic syndrome and preserved kidney function during the course of IMN), the first line of therapy was steroids with CYF used in addition to nephroprotective treatment. Due to poor tolerance to this treatment and its inefficacy, the decision was made to convert immunosuppressive therapy to CsA. On the third day of the treatment, despite normal serum drug concentration, AKI symptoms were observed. An analogous situation recurred after a few weeks, at an attempt to initiate treatment with TAC (AKI observed after three doses of the drug). Considering the symptoms, it was decided to exclude TAC from the treatment, which resulted in a quick return of diuresis and renal parameter improvement. Kidney function was restored rapidly following CNI discontinuation, confirming the supposition that AKI had been caused by those drugs.

CNIs are drugs that may exert a potentially toxic effect in the kidneys, which in turn might increase the risk of renal insufficiency progression in patients. This dose-independent risk [20] is especially significant in patients with initially deteriorated kidney function and concomitant tubulointerstitial changes in biopsy. In the described patient, the aforementioned risks of AKI were absent. The patient presented 
good kidney function before treatment, with only minor interstitial lesions observed in the biopsy.

Moreover, the drug dose applied was lower than the one suggested in the recommendations ( $5 \mathrm{mg} / \mathrm{kg} /$ day), and the serum drug concentration remained within the approved limits during the onset of symptoms. TAC concentration was not checked, as the reaction occurred almost immediately after its administration and the drug concentration would most probably not have reached the therapeutic level. Based on our experience in transplantation, the first drug concentration measurement should be performed about 4 days after treatment initiation. The patient presented arterial hypertension that was well-controlled pharmacologically; surprisingly, it did not deteriorate during the episode of AKI.

Our patient did not develop any of the most common adverse effects associated with CNIs namely, neurological symptoms, a decline in hypertension or glycemic control, hirsutism, or gingival hyperplasia [21], presumably due to the short treatment period. He also did not develop the HUS symptoms, which have been previously reported to occur during treatment with drugs of this class [22]. However, the presence of AKI with oliguria following only a few drug doses may argue in favor of the vascular background of this complication (arterial vessel contraction). Other arguments suggestive of this background may be the use of angiotensin convertase inhibitors, diuretics, and significant proteinuria with hypoalbuminemia observed in laboratory findings in our patient. All these circumstances are risk factors for AKI in patients with massive nephrotic syndrome. However, this complication occurred only after instigation of treatment with CNIs and reversed quickly and completely after their withdrawal, without any modification in the concomitant treatment. This argues in favor of the toxic activity of these drugs in our patient. Considering the rapid return of diuresis and renal function improvement after drug discontinuation, no repeated renal biopsy was performed. The examination of the blood flow in small renal vessels indicated an increase in vascular resistance during the course of CNI use, which normalized after drug discontinuation. No changes in blood flow in large kidney vessels were observed.

So far, very little data has been gathered about the side effects of CNIs in patients with IMN. In one study, 15 out of 41 patients reported the presence of side effects, among which the most common included gingival hypertrophy, nausea, and muscle cramps. The number of side effects did not correlate with the duration of treatment [23]. In a study by Howman et al. that included 36 patients affected by IMN and treated with CsA, the authors observed deteriorating kidney function, but only over long observation; they did not report AKI in their patients during the first 2 years of follow-up [24].

In a recently published, large study including 408 IMN patients treated with TAC, this drug proved to be especially effective in reducing proteinuria [25]. The most frequently observed side effect was a decline in renal function, as an eGFR reduction of at least $40 \%$ occurred in $10.5 \%$ of patients, whose eGFR levels recovered after a reduction in TAC dose or drug withdrawal. In 14 of those patients, a decrease of eGFR $>50 \%$ was observed during TAC treatment, and none of them recovered the eGFR levels after the treatment discontinuation. In this study, the development of eGFR decline appeared to be time dependent, and could occur at any time during TAC treatment [25]. However, the authors do not describe AKI in any patient in an early period after the first drug intake. Nevertheless, since the eGFR decline occurred during TAC treatment, nephrotoxicity of TAC should be considered for safety reasons.

Similarly, in the Ramachandran et al. study, which assessed 35 patients with IMN receiving TAC combined with corticosteroids versus patients treated with modified Ponticelli regimen, the authors observed a significantly higher incidence of nephrotoxicity in the TAC group. Patients with nephrotoxicity had higher TAC levels $(>8 \mathrm{ng}$ / $\mathrm{mL}$ ) at the time of diagnosis and the nephrotoxicity did not resolve in any cases following a TAC dose reduction. Patients treated with TAC experienced a significant eGFR reduction at the end of the 12th month of therapy. The authors did not report AKI in any patient, and their explanation for the increase in serum creatinine and reduction in eGFR was potential nephrotoxic effect associated with TAC therapy [26]. We cannot exclude the possibility that the decline in renal function in IMN patients is caused solely by the advancement of disease.

There is a lack of reports concerning AKI following CNI administration in patients treated for MN. The reported case urges us to be cautious regarding ambulatory initiation of CNIs in patients presenting MN, particularly if we observe features of the nephrotic syndrome. The clinician is obliged to educate the patient to consult a doctor immediately after observing a sudden reduction in the amount of urine passed, and to monitor their kidney function closely.

Acknowledgements We would like to thank Ms Grażyna Laskowska for correction of the English version.

Author Contributions MG, AP, AZ-B and IK contributed to managing the patient. MW-D contributed to analyzing and interpreting the histopathological findings. IK contributed to analyzing the gathered data. MG, AP, IK, MN and ZN contributed to writing the manuscript. All authors read and approved the final manuscript.

Availability and Data All the data used to write this case report is contained within the article.

\section{Compliance with Ethical Standards}

Funding All the costs of preparing the manuscript were covered by the authors themselves. 
Conflict of interest M. Goździk, A. Płuciennik, A. Zawiasa-Bryszewska, M. Nowicka, Z. Nowicka, M. Wągrowska-Danilewicz, and I. Kurnatowska declare that they have no conflict of interest that might be relevant to the contents of this article.

Informed consent Written informed consent was obtained from the patient for publication of this case report and any accompanying images. A copy of the written consent may be requested for review from the corresponding author.

Open Access This article is distributed under the terms of the Creative Commons Attribution-NonCommercial 4.0 International License (http://creativecommons.org/licenses/by-nc/4.0/), which permits any noncommercial use, distribution, and reproduction in any medium, provided you give appropriate credit to the original author(s) and the source, provide a link to the Creative Commons license, and indicate if changes were made.

\section{References:}

1. Perkowska-Ptasińska A, Bartczak A, Wagrowska-Danilewicz M, Halon A, Okoń K, Woźniak A, et al. Clinicopathologic correlations of renal pathology in the adult population of Poland. Nephrol Dial Transplant. 2017;32:209-18.

2. Jefferson JA, Couser WG. Therapy of membranous nephropathy associated with malignancy and secondary causes. Semin Nephrol. 2003;23:400-5.

3. Passos EM, Legallicier B, Godin M. Membranous nephropathy. Rev Prat. 2003;53:2033-8.

4. Ponticelli C, Passerini P. The place of cyclosporin in management of primary nephrotic syndrome. Biodrugs. 1999;12:327-41.

5. Polanco N, Gutiérrez E, Covarsí A, Ariza F, Carreño A, Vigil A, et al. Spontaneous remission of nephrotic syndrome in idiopathic membranous nephropathy. J Am Soc Nephrol. 2010;21:697-704.

6. Coresh J, Turin TC, Matsushita K, Sang Y, Ballew SH, Appel LJ, Arima H, Chadban SJ, Cirillo M, Djurdjev O, Green JA, Heine GH, Inker LA, Irie F, Ishani A, Ix JH, Kovesdy CP, Marks A, Ohkubo T, Shalev V, Shankar A, Wen CP, de Jong PE, Iseki K, Stengel B, Gansevoort RT, Levey AS. Decline in estimated glomerular filtration rate and subsequent risk of end-stage renal disease and mortality. JAMA. 2014;311:2518-31.

7. Waldman M, Austin HA 3rd. Treatment of idiopathic membranous nephropathy. J Am Soc Nephrol. 2012;23:1617-30.

8. Radhakrishnan J, Cattran DC. The KDIGO practice guideline on glomerulonephritis: reading between the (guide)lines-application to the individual patient. Kidney Int. 2012;82:840-56.

9. Myers BD, Newton L. Cyclosporine-induced chronic nephropathy: an obliterative microvascular renal injury. J Am Soc Nephrol. 1991;2:45-52.

10. Naesens M, Kuypers DR, Sarwal M. Calcineurin inhibitor nephrotoxicity. Clin J Am Soc Nephrol. 2009;4:481-508.

11. Höcherl K, Kees F, Krämer BK, Kurtz A. Cyclosporine A attenuates the natriuretic action of loop diuretics by inhibition of renal COX-2 expression. Kidney Int. 2004;65:2071-80.
12. Mihatsch MJ, Kyo M, Morozumi K, Yamaguchi Y, Nickeleit V, Ryffel B. The side-effects of ciclosporine-A and tacrolimus. Clin Nephrol. 1998;49:356-63.

13. Dieperink H, Starklint H, Leyssac PP, Kemp E. Glomerulotubular function in cyclosporine-treated rats. A lithium clearance, occlusion time/transit time and micropuncture study. Proc Eur Dial Transplant Assoc Eur Ren Assoc. 1985;21:853-9.

14. Perico N, Dadan J, Remuzzi G. Endothelin mediates the renal vasoconstriction induced by cyclosporine in the rat. J Am Soc Nephrol. 1990;1:76-83.

15. Ojo AO, Held PJ, Port FK, Wolfe RA, Leichtman AB, Young EW, Arndorfer J, Christensen L, Merion RM. Chronic renal failure after transplantation of a nonrenal organ. N Engl J Med. 2003;349:931-40

16. Williams D, Haragsim L. Calcineurin nephrotoxicity. Adv Chronic Kidney Dis. 2006;13:47-55.

17. Kahan BD. Cyclosporine. N Engl J Med. 1989;321:1725-38.

18. Vieira JM Jr, Noronha IL, Malheiros DM, Burdmann EA. Cyclosporine-induced interstitial fibrosis and arteriolar TGF-beta expression with preserved renal blood flow. Transplantation. 1999;68:1746-53.

19. Sigal NH, Dumont F, Durette P, Siekierka JJ, Peterson L, Rich DH, Dunlap BE, Staruch MJ, Melino MR, Koprak SL, et al. Is cyclophilin involved in the immunosuppressive and nephrotoxic mechanism of action of cyclosporin A? J Exp Med. 1991;173:619-28.

20. Ponticelli C. Glucocorticoids and immunomodulating agents. In: Ponticelli C, Glassock RJ, editors. Treatment of primary glomerulonephritis. 2nd ed. New York: Oxford University Press; 1997. p. 25-77.

21. Webster AC, Woodroffe RC, Taylor RS, Chapman JR, Craig JC. Tacrolimus versus ciclosporin as primary immunosuppression for kidney transplant recipients: meta-analysis and meta-regression of randomised trial data. BMJ. 2005;331:810.

22. Ponticelli C. De novo thrombotic microangiopathy. An underrated complication of renal transplantation. Clin Nephrol. 2007;67:335-40.

23. Guasch A, Suranyi M, Newton L, Hall BM, Myers BD. Short-term responsiveness of membranous glomerulopathy to cyclosporine. Am J Kidney Dis. 1992;20:472-81.

24. Howman A, Langdon MM, Ferguson C, Adu D, Feehally J, Gaskin GJ, Jayne DR, O’Donoghue D, Boulton-Jones M, Mathieson PW. Immunosuppression for progressive membranous nephropathy: a UK randomised controlled trial. Lancet. 2013;381:744-51.

25. Qin HZ, Liu L, Liang SS, Shi JS, Zheng CX, Hou Q, Lu YH, Le WB. Evaluating tacrolimus treatment in idiopathic membranous nephropathy in a cohort of 408 patients. BMC Nephrol. 2017;18:2.

26. Ramachandran R, Hn HK, Kumar V, Nada R, Yadav AK, Goyal A, Kumar V, Rathi M, Jha V, Gupta KL, Sakhuja V, Kohli HS. Tacrolimus combined with corticosteroids versus modified Ponticelli regimen in treatment of idiopathic membranous nephropathy: randomized control trial. Nephrology. 2016;21:139-46. 